\title{
KINETOSTATIČKA ANALIZA PLANETARNIH MENJAČA U PROGRAMU MSC ADAMS
}

\section{KINETOSTATIC ANALISYS OF PLANETARY TRANSMISSIONS USING MSC ADAMS SOFTWARE}

\author{
Srđan Mrđa, Fakultet tehničkih nauka, Novi Sad
}

\section{Oblast - MAŠINSTVO}

Kratak sadržaj - U radu je, primjenom simulacija $u$ softveru MSC Adams View, izvršeno određivanje karakteristika dva modela automatskog mjenjača. U pitanju su modeli 7G-Tronic $i$ 9G-Tronic te se tačnost dobijenih rezultata utvrdila pomoću proračuna primjenom opšteprihvaćenih Vilisovih jednačina. Karatkeristike koje su u pitanju su: broj obrtaja i obrtni moment na svim elementima mjenjača, provjera prenosnog odnosa te određivanje stepena korisnosti u svim stepenima prenosa.

Ključne reči: Simulacije, automatski mjenjač, Vilisova jednačina

\begin{abstract}
The work, using simulations in software MSC Adams View, determined the characteristics of two automatic gearbox models. Two models that are being analyzed are 7G-Tronic and 9G-Tronic. Accurasy of the obtained results is validated by using calculations with Willis equations. Analyzed characteristics are: revolutions per minute and torque of all gearbox elements, checkup of transmission ratios and determening level of efficiency in every gear ratio.
\end{abstract}

Keywords: Simulation, automatic gearbox, Willis equation

\section{UVOD}

U automobilskoj industriji desio se veliki iskorak pronalaskom automatske transmisije. Pronalazak automatske transmisije datira još iz prve polovine dvadesetog vijeka. Ovaj vid prenosa je prešao dug put adaptacije i dan danas se usavršava, posebno u posljednjih nekoliko decenija kada elektronika $u$ auto-industriji uzima primat. Upravo iz ovog razloga, primjena simulacija u projektovanju i izučavanju karakteristika automatskog mjenjača ima veliki značaj.

Pomoću simulacija moguće je sistemsko posmatranje i uočavanje eventualnih nepravilnosti, problema koji se javljaju u automatskim mjenjačima i ispitivanje mogućnosti njihovog otklanjanja. Takođe, na ovaj način se mogu ustanoviti karakteristike automatskog mjenjača dok se isti nalazi u razvojnoj fazi. Na ovaj način se smanjuju troškovi i vrijeme razvojnog procesa, te su simulacije i primjena softvera uzeli primat u riješavanju raznih inženjerskih problema današnjice.

\section{NAPOMENA:}

Ovaj rad proistekao je iz master rada čiji mentor je bio dr Nenad Poznanović, docent.
Osnovni cilj ovog rada jeste primjena simulacija $u$ softveru MSC Adams View za određivanje karakteristika dva modela automatskog mjenjača. U pitanju su $7 \mathrm{G}-$ Tronic i 9G-Tronic automatski mjenjači, koji predstavljaju dvije generacije mjenjača veoma različitih po konstrukciji, te su zato odabrani za ovaj rad. Karakteristike mjenjača koje su obrađene u ovom radu su: broj obrtaja i obrtni moment na svim elementima mjenjača, provjera prenosnog odnosa te određivanje stepena korisnosti $u$ svim prenosnim odnosima. Za potvrdu tačnosti dobijenih rezultata $\mathrm{u}$ pomenutom softveru korišten je proračun $\mathrm{u}$ Mathcad-u koji se bazina na Vilisovim (eng. Willis) jednačinama. Vilisove jednačine su opšteprihvaćene jednačine za proračun navedenih karakteristika planetnih prenosnika. Na ovaj način se želi prikazati validnost dobijenih rezultata, te mogućnost modelovanja i simuliranja ovakve vrste sistema u MSC Adams View softveru.

Takođe, detaljno je prikazan postupak nastanka oba modela automatskog mjenjača koji su u potpunosti parametrizovani. Uz primjenu mogućnosti koji ovaj softver pruža, izbjegla se potreba za stvaranjem pojedinačnih modela mjenjača za svaki stepen prenosa te se uz pomoć intuitivnog menija mogu vršiti izmjene stepeni prenosa što značajno olakšava simulacije i poređenje rezultata.

\section{PLANETNI PRENOSNIK}

Planetni prenosnik, prikazan na slici 1 ., najznačajniji je element u oba razmatrana modela automatskog mjenjača $i$ veoma je značajan za proračun prikazan u radu, te će $u$ nastavku biti prikazana njegova konstrukcija. Prosti planetni prenosnik sastoji se od centralnog zupčanika, nosača, ozubljenog vijenca i nekoliko takozvanih satelita koji predstavljaju zupčanike koji se nalaze između centralnog zupčanika i ozubljenog vijenca. Planetni zupčanici se obrću oko svog vratila koje predstavlja njihov nosač i oko glavne ose centralnog zupčanika. Obrtni moment je raspoređen između satelita kako bi se omogućilo ravnomjerno opterećenje na svakog od njih. Prenosni odnos stacionarnog planetnog prenosnika predstavlja odnos broja zubaca ozubljenog vijenca i centralnog zupčanika. Važno je napomenuti da se broj zubaca ozubljenog vijenca $u$ proračunima predstavlja kao negativan broj zbog unutrašnjeg ozubljenja. Niz prednosti kao što su kompaktna konstrukcija, sposobnost prenosa velikog obrtnog momenta i sposobnost realizacije velikog broja prenosnih odnosa, čine ovaj prenosnik idealnim za primjenu u automatskim mjenjačima [1]. 


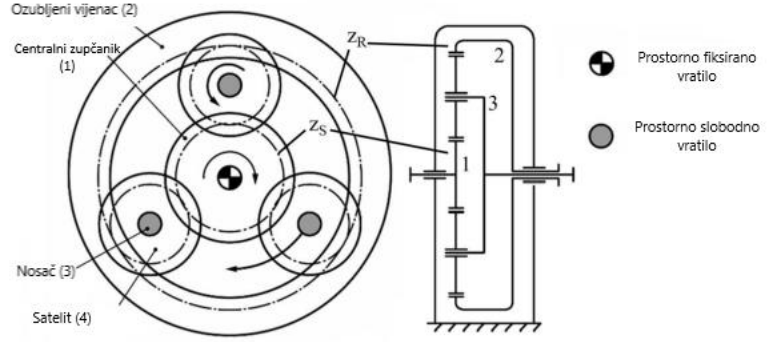

Slika 1. Planetni prenosnik [1]

\subsection{Vilisova jednačina}

Najznačajnija jednačina $u$ primjeni prilikom analize $\mathrm{i}$ proračuna planetnih prenosnika je Vilisova (eng. Willis) jednačina. Ona u svojoj osnovnoj formi izgleda:

$n_{s} \cdot d_{s}=n_{n} \cdot\left(d_{s}+d_{c}\right)-n_{c} \cdot d_{c}$

$n_{s}$ - broj obrtaja satelita,

$d_{s}-$ prečnik satelita,

$n_{n}$ - broj obrtaja nosača satelita,

$d_{c}-$ prečnik centralnog zupčanika,

$n_{c}$ - broj obrtaja centralnog zupčanika,

$d_{v}$ - prečnik ozubljenog vijenca.

U ovoj formi Vilisova jednačina povezuje kretanja satelita, nosača satelita i centralnog zupčanika, te joj je potrebna dodatna izmjena kako bi se koristila u proračunu planetnih prenosnika sa ozubljenim vijencem. U slučaju kada se primjenjuje za spoj satelita i ozubljenog vijenca osnovna Vilisova jednačina ima oblik:

$$
n_{s} \cdot d_{s}=n_{n} \cdot\left(d_{s}-d_{v}\right)+n_{v} \cdot d_{v}
$$

Ovakva verzija jednačine, uz određene izmjene primenjenih veličina, korištena je u proračunu ovog rada za oba modela automatskog mjenjača.

\section{7G-TRONIC AUTOMATSKI MJENJAČ}

7G-Tronic je prvi svjetski sedmostepeni automatski mjenjač proizveden 2003. godine u Mercedes-Benzu. Ovaj model predstavlja petu generaciju automatskih mjenjača koji su konstruisani i proizvedeni u Mercedes-Benz fabrici automobila. Kako bi ostvarili devet stepeni prenosa, sedam stepeni za hod unaprijed i dva za hod unazad, uz zadržavanje optimalnog ukupnog raspona prenosnog odnosa, navedeni model koristi Ravinjon (fr. Ravigneaux) planetni prenosnik zajedno sa dva prosta planetna prenosnika. Ravinjon planetni prenosnik primijenjen $\mathrm{u}$ ovom modelu se sastoji od jednog centralnog zupčanika, dva satelita od kojih je jedan duži i povezan je sa malim ozubljenim vijencem dok je drugi satelit kraći i predstavlja vezu između velikog ozubljenog vijenca i dugog satelita. Takođe, bitan element ovog planetnog prenosnika jeste i planetni nosač koji omogućava prenos snage na satelite $i$ vezu sa centralnim zupčanikom. Kao kontrolni elementi koriste se tri spojnice i četiri kočnice koje omogućavaju ostvarivanje velikog broja prenosnih odnosa [2].

Prethodno opisane Vilisove jednačine primijenjene su u proračunu 7G-Tronic i 9G-Tronic mjenjača. Svaki prosti planetni prenosnik se u proračunu opisuje sa dvije Vilisove jednačine, dok se Ravinjon planetni prenosnik $u$ proračunima može posmatrati kao dva prosta planetna prenosnika sa zajedničkim nosačem satelita te se opisuje sa četiri Vilisove jednačine. Kretanje 7G-Tronic modela se, dakle, može opisati uz pomoć osam Vilisovih jednačina. Ovom sistemu je za kompletan proračun potrebno pridružiti: jednačine koje izražavaju stalne veze između elemenata prenosnika, jednačine koje opisuju veze između elemenata uspostavljene spojnicama u pojedinim stepenima prenosa, te jednačine kojima se propisuje koji su elementi zaustavljeni kočnicama u pojedinim stepenima prenosa. Takođe, bitno je naglasiti, da se jednačine rješavaju $u$ početnom obliku, bez transformacije, primjenom numeričkih metoda koje se primijenjuju i za nelinearne jednačine. U tabeli 1. je prikazano poređenje rezultata dobijenih simulacijama u MSC Adams programu i rezultata dobijenih proračunom pomoću Vilisovih jednačina.

Model 7G-Tronic automatskog mjenjača je veoma specifičan po svojoj konstrukciji. Kao što je već rečeno, sastoji se iz dva prosta planetna prenosnika i jednog Ravinjon planetnog prenosnika. Za razliku od prostih planetarnih prenosnika koji se mogu konstruisati uz pomoć Adams Machinery Gear opcije, Ravinjon (fr. Ravigneaux) planetni prenosnik sa spregnutim satelitima na zajedničkom nosaču se na ovaj način ne može konstruisati, te se ovaj programski alat nije koristio u izradi ovog modela, ali je bio veoma značajan za kreiranje modela njegovog nasljednika, 9G-Tronic automatskog mjenjača. Svi zupčanici i ozubljeni vijenci su kreirani kao cilindri te im se, uz pomoć prethodno definisanih parametara, zadaju funkcije zupčanika. Takođe, prilikom definisanja ulaznih parametara modela kao što su širina planetnih prenosnika, broj zubaca svih zupčanika mjenjača pa čak i uglova između krakova nosača satelita, ostvarena je potpuna prametrizacija modela koja omogućava laku izmijenu modela bez narušavanje njegove funkcionalnosti. Prethodno opisani model je prikazan na slici 2.

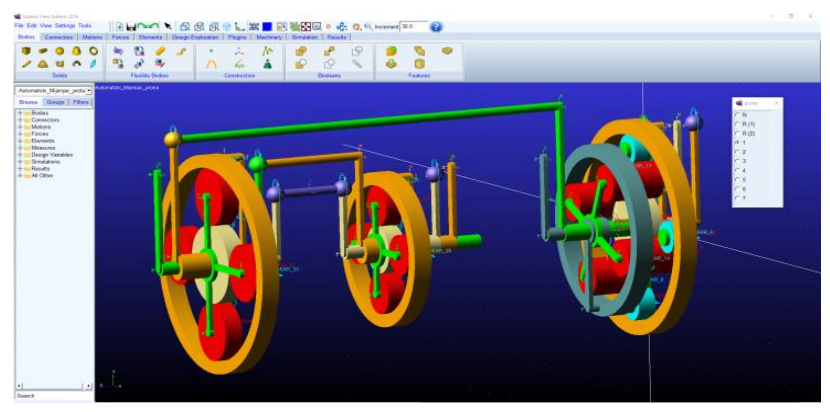

Slika 2. Model 7G-Tronic mjenjača u MSC Adams-u

Poređenje nekoliko dobijenih rezultata simulacija i proračuna su prikazani u nastavku teksta u tabeli 1 .

Tabela 1. Poređenje rezultata 7G-Tronic modela

\begin{tabular}{|c|c|c|c|}
\hline & $\begin{array}{c}\text { Rezultati } \\
\text { proračuna u } \\
\text { Mathcad-u }\end{array}$ & $\begin{array}{c}\text { Rezultati } \\
\text { simulacija u } \\
\text { MSC Adams-u }\end{array}$ & $\begin{array}{c}\text { Razlike } \\
{[\%]}\end{array}$ \\
\hline $\begin{array}{c}\text { Prenosni odnos 3 } \\
\text { stepena prenosa }\end{array}$ & 1,921 & 1,921 & 0 \\
\hline $\begin{array}{c}\text { Stepen korisnosti } \\
\text { 2 stepena prenosa }\end{array}$ & 0,9653 & 0,9809 & 1,59 \\
\hline $\begin{array}{l}\text { Stepen korisnosti } \\
\text { 5 stepena prenosa }\end{array}$ & 1 & 0,9981 & 0,19 \\
\hline
\end{tabular}




\section{9G-TRONIC AUTOMATSKI MJENJAČ}

Nasljednik prethodno opisanog 7G-Tronic modela je 9GTronic automatski mjenjač koji ima značajna unaprjeđenju u odnosu na svog prethodnika. Tehnički i ekonomski napredak je evidentan i predstavljen je kroz deset stepeni prenosa sa deset glavnih komponenti, dok je 7G-Tronic imao devet stepeni prenosa sa jedanaest glavnih komponenti.

Dakle, veći broj stepeni prenosa sa jednostavnijom konstrukcijom. Sastoji se od četiri standardna prosta planetarna prenosnika sa šest upravljačkih elemenata, tri spojnice i tri kočnice.

Za moderan automatski mjenjač sa više od osam stepeni prenosa i veliki ukupni prenosni odnos izrazito dugo ulazno vratilo je karakteristično. Ulazno vratilo je, pored centralnog zupčanika prvog planetnog prenosnika, spregnuto i sa četvrtim planetnim prenosnikom [3].

Vilisove jednačine su primijenjene i u proračunu ovog modela mjenjača, a nekoliko rezultata proračuna je prikazano u tabeli 2. zajedno sa rezultatima simulacija ovog modela u MSC Adams-u.

Modelovanje 9G-Tronic mjenjača je na početku veoma slično prethodno prikazanom modelu. Prvi korak prilikom modelovanja jeste selekcija Create new model opcije iz predloženog menija, odabir imena, mjernih jedinici koje su najadekvatnije za dati model te foldera u koji će model biti sačuvan. Nakon toga je potrebno definisati ulazne parametre modela u opciji Design Variables pomoću kojih je veoma jednostavno vršiti naknadne izmjene modela. Nakon definisanja parametara modela, potrebno je definisati tačke sistema, pomoću kojih je jednostavno prostorno definisati dijelove sistema i vršiti eventualne izmjene.

Za razliku od prethodno opisanog 7G-Tronic modela, ovaj automatski mjenjač se sastoji od isključivo prostih planetarnih prenosnika što značajno olakšava modelovanje. Upravo ova osobina omogućila je upotrebu Adams Machinery Gear opcije, pomoću koje su konstruisani planetarni prenosnici.

Ova opcija automatski konstruiše sve zupčanike i zupčaste vijence, njihove međusobne veze i omogućava jednostavnije simulacije. Naravno, prethodno tačno definisani ulazni parametri i tačke sistema su neophodni za pravilno funkcionisanje. Na slici 3. je prikazan model 9G-Tronic u trećem stepenu prenosa.

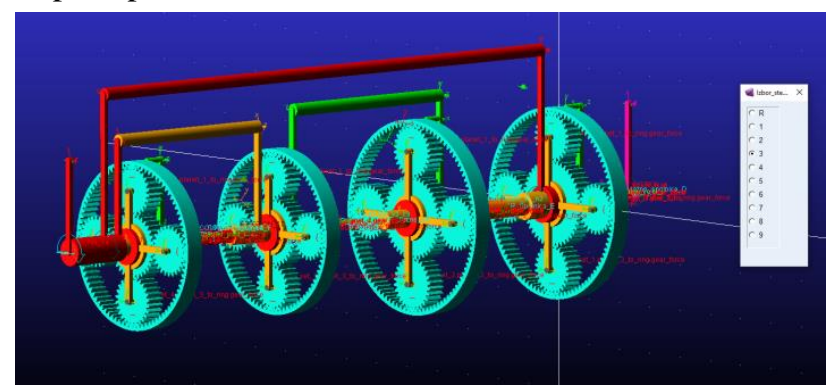

Slika 3. Model 9G-Tronic mjenjača u MSC Adams-u

$\mathrm{Na}$ oba modela automatskog mjenjača u MSC Adams-u može se primijetiti da program MSC Adams prvenstveno služi za dinamičke simulacije i dobijanje korisnih rezultata o modelu, ali modeli vizuelno ne predstavljaju vijernu imitaciju stvarnog automatskog mjenjača.
Tabela 2. Poređenje rezultata 9G-Tronic modela

\begin{tabular}{|c|c|c|c|}
\hline & $\begin{array}{c}\text { Rezultati } \\
\text { proračuna } \mathrm{u} \\
\text { Mathcad-u }\end{array}$ & $\begin{array}{c}\text { Rezultati } \\
\text { simulacija u } \\
\text { MSC Adams-u }\end{array}$ & $\begin{array}{c}\text { Razlike } \\
{[\%]}\end{array}$ \\
\hline $\begin{array}{c}\text { Prenosni odnos } \\
\text { 2 stepena } \\
\text { prenosa }\end{array}$ & 3,333 & 3,333 & 0 \\
\hline $\begin{array}{c}\text { Stepen } \\
\text { korisnosti 1 } \\
\text { stepena prenosa }\end{array}$ & 0,947 & 0,9401 & 0,73 \\
\hline $\begin{array}{c}\text { Obrtni moment } \\
\text { na centralnom } \\
\text { zupčaniku } \\
\text { drugog prostog } \\
\text { planetnog } \\
\text { prenosnika (3 } \\
\text { stepen prenosa) }\end{array}$ & 0,306 & 0,3056 & 0,04 \\
\hline
\end{tabular}

\section{ZAKLJUČAK}

Automatski mjenjači imaju veoma značajnu ulogu u automobliskoj industriji današnjice. Ova činjenica stavlja imperativ na izučavanje karakteristika i parametara automatskog mjenjača u cjelini i njegovih pojedinačnih elemenata.

U ovom radu je izvršeno modelovanje dva modela automatskog mjenjača kao i proračun željenih parametara. $\mathrm{Na}$ osnovu toga, cilj rada je pokazati primjenljivost $M S C$ Adams View softvera za ovakve vrste simulacije. Dobijeni rezultati simulacija za oba modela su jednaki kao i proračunate vrijednosti tih parametara što ukazuje na kvalitetan i funkcionalan model.

Veoma važan detalj jeste potpuna parametrizacija oba $M S C$ Adams View modela. Ovo omogućava izmjene modela u vidu promjene broja zubaca pojedinih elemenata, širine planetarnih prenosnika ili modula zupčanika bez uticaja na funkcionalnost modela.

Ovakvim vidom implementacije dizajn parametara ostvaruju se jednostavne izmjene modela i promatranje uticaja ovih promjena na njegove izlazne veličine, što je od ključnog značaja prilikom projektovanja mjenjača ili razmatranja njegovih karakteristika. Takođe, prednost ovakve vrste modela jeste jednostavnost izmijene stepena prenosa uz pomoć tome namijenjenog menija. Na ovaj način se izbjegava kreiranje mnoštva različitih modela za svaki stepen prenosa mjenjača i omogućava jednostavno poređenje željenih rezultata.

Kreiranjem dva modela automatskog mjenjača, cilj je bio pokazati mogućnost modelovanja planetnih prenosnika na dva potpuno različita načina, ali ipak dobiti konkretne i tačne rezultate.

Proračun je vršen, kao što se moglo vidjeti, uz pomoć Vilisovih jednačina. Jedina odstupanja između dobijenih rezultata simulacija i proračuna se mogu uočiti u stepenu korisnosti. Razlog ovakve razlike jeste uticaj gubitaka u ležajevima vratila mjenjača koji je obuhvaćen prilikom MSC Adams View simulacije, dok je u Mathcad proračunu zanemaren. 
Sljedeći koraci u istraživanju bi trebali obuhvatiti detaljnu analizu stepena korisnosti i dobijenih razlika u rezultatima, primjenu ulaznih parametara stvarnog pogonskog agregata te istraživanje uticaja hidrodinamičkog pretvarača na dobijene rezultate.

\section{LITERATURA}

[1] Optimized Shift Control in Automatic Transmissions with respect to Spontaneity, Comfort and Shift Loads, Peng Dong, Fakultät für Maschinenbau, RuhrUniversität, Bohum, 2015.

[2] Siebengang-Automatikgetriebe von Mercedes-Benz, Jürgen Greiner, Günter Indlekofer, Harald Nauerz, Jens Dorfschmid, Tobias Gödecke, Christoph Dörr, ATZ 105, 920-930(2003).

[3] THE NEW AUTOMATIC TRANSMISSION 9GTRONIC by Mercedes-Benz, Christoph Dörr, Henrik Kalczynski, Anton Rink, Marcus Sommer, ATZ 116, 20-25(2014).

\section{Kratka biografija:}

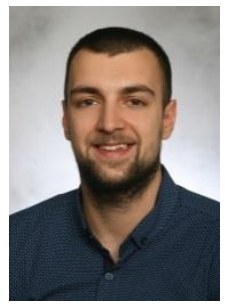

Srđan Mrđa rođen je u Lazarevcu 1996. god. Diplomski rad na Fakultetu tehničkih nauka iz oblasti Tehnička logistika $i$

simulacije - Primena simulacija u

projektovanju skladišnih sistema odbranio je 2020.god.

kontakt: mrdjas96@hotmail.com 